For example, researchers recently examined glial cells, an enigmatic type of cell found in the brain, and by analysing the mechanical properties of the cells found that they could not act as glue or as support for neurons as had previously been believed (Y. B. Lu et al. Proc. Natl Acad. Sci. USA 103, 17759-17764; 2006).

Other examples have included a predictive model for spindle alignment - a step that tells cells how to divide - based on physical forces inside the cell induced by its adhesion to a surface ( $M$. Théry et al. Nature 447, 493-496; 2007), and an analysis of cytoskeleton behaviour in response to cell stretching (X. Trepat et al. Nature 447, 592-595; 2007).

In such endeavours, efforts must be made to ensure that a collaboration is truly intellectually productive for all disciplines involved. The initial urge may be for biologists to go to physicists or mathematicians for help in developing techniques or building models to answer purely biological questions, creating a one-way relationship. Alternatively, the allure of simple, elegant models may have some theorists working to ends that don't necessarily provide biological insight. But in the best examples of interdisciplinary work, insight and enlightenment are mutual. Biologists get a chance to answer key questions in their field while mathematicians and physicists develop and apply tools that better inform their understanding of the natural world. Otherwise, calling such work 'interdisciplinary' is little more than lip service.

If cell biologists are truly to engage physicists and vice versa, a better sense that both are in this ride together is necessary. The papers mentioned above involve exploring physical forces
"Marrying measurable physical forces to cellular chemistry in a meaningful way promises to push biology far beyond today's biochemistry." acting on a cellular scale. Marrying those measurable physical forces to cellular chemistry in a meaningful way promises to push biology far beyond today's biochemistry. It is a challenge that could engage research for decades. And physics, in particular, is needed more than ever.

\section{Space for capitalism}

\section{Rich people who play with rockets should be encouraged, but not subsidized.}

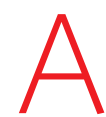
lthough British prime minister Edward Heath turned a fresh phrase in castigating "the unacceptable face of capitalism" in the 1970s, he was hardly unearthing something new. Aspects of capitalism have always suffered from unpalatable appearances, sometimes coinciding with genuine flaws.

But capitalists' knack for opening up markets and creating wealth has benefited society sufficiently to make some of its practitioners' faces more than acceptable. Few fit more squarely in that camp than those who have made their fortunes through computers and the Internet. "The largest single legal creation of wealth we've witnessed on the planet", as venture-capitalist John Doerr has termed it, was brought about by imaginatively finding ways to provide things that made lives and businesses more efficient, more effective, more fun, or some combination of all three.

Now a few of these people are devoting some of their acquired fortunes to the as-yet-untested business of inexpensive space flight (see page 988). Jeff Bezos, the founder of Amazon.com, has gathered together the expertise he thinks is needed to build rockets that will fly passengers first to the edge of space, later to orbit. Elon Musk, one of the begetters of PayPal, is building a range of rockets, some tailored to traditional satellite markets, some to taking people to the International Space Station. SpaceShipOne, which three years ago won the Ansari X prize for flying to an altitude of 100 kilometres and back twice within a fortnight, did so with the financial backing of Paul Allen, one of the founders of Microsoft. SpaceShipTwo is being developed in partnership with the Virgin Group, chaired by Richard Branson, a popular capitalist from a different background.

At the very least, this activity is likely to provide some thrills for wealthy customers - and cheaper launch options for certain types of satellite. Today's established rocket companies are vast concerns deeply embedded in the military-industrial complexes of various nations; it is a fair assessment that entrepreneurial competition will shake them up a bit.

At best, one or more of these companies might actually find ways to make the launch of private citizens into orbit cheap and routine. This wouldn't just allow a lot of people to fulfil their childhood fantasies; it would also make it cheaper for governments to put people into orbit - a capability that a number of them currently maintain at very high cost for little clear benefit. And it would render the eventual exploration of other bodies in the Solar System more affordable than it is today.

This somewhat distant prospect, however, should not obscure various grounded truths. One is that getting cheap, reusable vehicles into orbit and back again is not going to be easy, and may well prove beyond the reach of current technologies.

There are also security concerns. Given that the technologies needed to circle round Earth are basically the same as those needed to lay waste to the ground below, their development cannot always be viewed as an unmitigated good. Some faces would be entirely unacceptable as owners

"It is a fair assessment
that entrepreneurial
competition will shake
established rocket
companies up a bit."
of what amounts to a privatized, intercontinental ballistic missile. The issue of who decides what constitutes 'acceptable' in that context remains unresolved.

Finally, it can be anticipated that some would-be space entrepreneurs will, given half a chance, seek subsidy from the public purse. Such calls should be treated with scepticism. Certain public-private partnerships may make sense, and the programmes so far offered by NASA to encourage the development of private-sector resupply craft for the space station seem to do so. But in general, those who believe in private spaceflight should pursue their dream at their own expense. 